\title{
O Ministério de Minas e Energia Elétrica Como Parte da Reforma na Administração Brasileira
}

\author{
WALDEMar José de CARVAlHo \\ Diretor da Divisão de Águas do M. A.
}

$\mathrm{N}$ dos tempos poe a menor dúvida de que, frente ao formidável progresso técnico mento econômico de um pais.

Para o Brasil, em especial, que dispõe de vastos recursos de energia hidráulica, ocupando, na estatística mundial, o 4..$^{\circ}$ lugar, abaixo apenas da Rússia, Canadá e Estados Unidos da América do Norte, então o problema aparece com maior destaque e digno de atenções e estudos mais aprofundados, com o fim de tornar o país mais rico e gozarem de maior conforto os seus habitantes.

E' verdade que apesar do muito que ainda se poderá fazer, o Govêrno vem dispensando especial carinho a tão importante problema nacional, dentro naturalmente dos recursos atuais e com o que permite a nossa estrutura administrativa.

Fato é que o executivo se convenceu de que a indústria da eletricidade, para ter o desenvolvimento que se faz necessário, precisa ficar subordinada não apenas a uma Divisão, mas a um Departamento que seja um dos órgãos componentes de um Ministério especializado. Daí, o significado de uma mensagem que foi encaminhada ao legislativo, em que se propõe a criação do Ministério de Minas e Energia Elétrica.

A criação dêsse novo Ministério atende, antes de mais nada, a razões técnicas, rigorosamente subordinadas às necessidades que visam ao desenvolvimento da economia nacional. E em tôrno dessas circunstâncias é que procuraremos fazer algumas considerações. bascadas na experiência do trabalho que vimos realizando na Divisão de Águas do Ministério da Agricultura, fixando aspectos mais importantes do problema.

Os técnicos desta Divisão, com experiência adquirida através de cêrca de 20 anos, na execução do Código de Águas e no trato das pesquisas concernentes a águas e energia elétrica, como colaboração apresentam a estruturação de um Departamento Nacional de Águas e Energia Elétrica que julgam atender, de modo satisfatóriơ, às finalidades que o Govêrno tem em vista.

A fim de oferecer rápida e objetiva compreensão das sugestões ora apresentadas, acompanham a dissertação em aprêço três organogramas. O pri- 
meiro, relativo à atual organização da Divisão de Águas; o segundo, referindo-se à atual organização do Departamento Nacional de Iluminação e Gás e, finalmente, o terceiro, que traduz a estruturação proposta para o Departamento Nacional de Águas e Energia Elétrica.

Dentro do esquema proposto, a organização do Departamento Nacional de Águas e Energia Elétrica resultará da fusão da Divisão de Águas com o Departamento Nacional de Iluminação e Gás. Por outro lado, dêste serão retirados os subórgãos relacionados com o gás e a iluminação pública, os quais passarão para a Prefeitura do Distrito Federal, em virtude de se tratar de serviços públicos tìpicamente municipais.

Vejamos, agora, quais as vantagens mais expressivas dessa fusão: além daquelas advindas da unificação dos órgãos e sua estruturação, destaca-se uma importante vantagem de ordem econômica, qual seja a de evitar, no novo Departamento, a criação onerosa de um serviço de Administração e de um não menos dispendioso laboratório de eletricidade. Tais indicações dispensam maiores comentários, já que são por demais evidentes para que entremos em minúcias.

Devemos, também, levar em conta certos aspectos concernentes à presente estrutura da Divisão de Águas e que se referem à transferência, para outros setores, de alguns de seus serviços.

Com efeito, na atual organização da Divisão de Águas, existe a Seção de Irrigação que, positivamente, por todos os motivos - técnicos e econômicos. - não cạbe no esquema de um Departamento de Águas e Energia Elétrica. $\mathrm{E}$ isso resulta da circunstância de que a irrigação possui problemas que the são peculiares e a execução de seus objetivos não se confunde com a de outras atividades relacicnadas diretamenet à de águas ou de energia elétrica.

Além disso, acresce outra razão especial: a irrigação, cuja importância e necessidade para extensas regiões brasileiras se tornam indiscutíveis, deveria ter tratamento adequado, ou seja, a atual seção de Irrigação deveria transferir-se para o Departamento Nacional de Produção Vegetal, constituindo uma nova Divisão que poderia ter esta denominação: "Irrigação e Conservação do Solo".

São assuntos, realmente, que se completam, sendo que o estudo dos problemas relacionados com a conservação do solo, feito através de um órgão especializado, viria preencher um claro na estruturação administrativa federal, além da matéria ser tratada mais racionalmente e com possibilidades maiores de êxito na sua prática.

Consideremos, agora, pròpriamente, o que deverá ser, sob ponto de vista técnico e administrativo o que ora se propõe criar, isto é, o Departamento Nacional de Águas e Energia Elétrica. A sua estruturação deverá pois obedecer à seguinte constituição:

a) 3 Divisões;

b) 1 Serviço de Administração;

c) 1 Serviço de Documentação; e

d) Auxiliares da Diretoria Geral, incluindo-se entre êles doís (2) Assistentes jurídicos. 
As Divisões componentes do Departamento serão as de Águas, Energia Elétrica e Fotogrametria, cada uma das quais deverá ser completada por uma "turma de administração" e auxiliares do Diretor.

A fim de que os trabalhos possam realizar-se dentro de uma sistemática técnica perfeitamente definida, à Divisão de Águas ficarão afetas tôdas as pesquisas e tarefas relacionadas com águas, enquanto que a de Energia Elétrica cuidará exclusivamente dos assuntos relacionados à indústria da eletricidade.

Passemos, a seguir, à enumeração das Seções que deverão compor a Divisão de Águas. Ei-las:

1. a) Hidrologia - (fluviometria; linimetria; pluviometria; estudos de regime; descargas sólidas; aferição de molinetes; laboratório hidráulico; previsão e anúncio de cheias e evaporação);

2. ${ }^{a}$ ) Energia Hidráulica - (estudos das fontes de energia hidráulica; avaliação do potencial hidráulico; classificação de cursos dágua; anteprojetos, orçamentos e obras);

3. a) Reservatórios e Cheias - (Seções barráveis; barragens; bacias de acumulação; remonte e assoreamento dos reservatórios). A Divisão de Energia Elétrica, por sua vez, compor-se-á das seguintes Seções;

1. ${ }^{\text {) }) ~ C o n c e s s o ̃ e s, ~ A u t o r i z a c ̧ o ̃ e s ~ e ~ E s t u d o s ~ E c o n o ̂ m i c o s ~-~(C o n c e s s o ̃ e s ~ e ~}$ autorizações para aproveitamentos de energia hidráulica; autorização para instalações de usinas termoelétricas; ampliação de sistemas elétricos; contratos; estudos econômicos relativos à indústria da eletricidade; projetos e orçamentos de usinas e instalações elétricas);

2. ${ }^{a}$ ) Fiscalização Técnica - (Fiscalização técnica das emprêsas produtơras e distribuidoras; fiscalização de obras; execução de obras relativas a usinas e instalações elétricas; laboratório de eletricidade; testagem de material; taxas e fiscalização dos contratos de fornecimento);

3. $\left.{ }^{a}\right)$ Fiscalização Contábil e Estatística Econômica - Fiscalização contábil das emprêsas produtoras e distribuidoras; tarifas; custo original e histórico; depreciação; obsolecência e estatísticas economicas); e

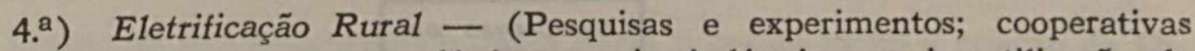
rurais elétricas; transmissões elétricas rurais; indústrias rurais; utilização de energia elétrica em sistema de irrigação; tarifas e taxas).

Nessa simples indicação das diferentes seções e suas atribuições não cabem aqui comentários específicos acêrca da importância que estas representam e que, de resto, elas constituem o próprio arcabouço técnicó-administrativo das Divisões. Sua existência e seu funcionamento dizem o amplo círculo de atividades que abarcam - a própria dinâmica da Divisão em geral.

Finalmente, passemos à 3 . $^{\text {a }}$ Divisão. Antes, porém, façamos algumas considerações em tôrno da matéria que ela irá consubstanciar.

Os estudos de aproveitamento de energia hidráulica, de bacias de acumulação e de linhas de transmissão, de que cuidam a Divisão de Águas e a de 
Energia Elétrica, estão na dependência, em grande parte, de mapas e plantas rigorosamente executadas, através de levantamentos terrestres e aéreos que expressem com fieldade a região que esteja sendo objeto da análise.

A tendência técnica moderna, na organização de cartas, se orienta no sentido dos levantamentos aéro-fotogramétrico, considerando o rigor que êles apresentam, assim como o aspecto relativo à economia e rapidez da realização.

\section{ORGANOGRAMA DA DIVISÃO DE ÁGUAS}

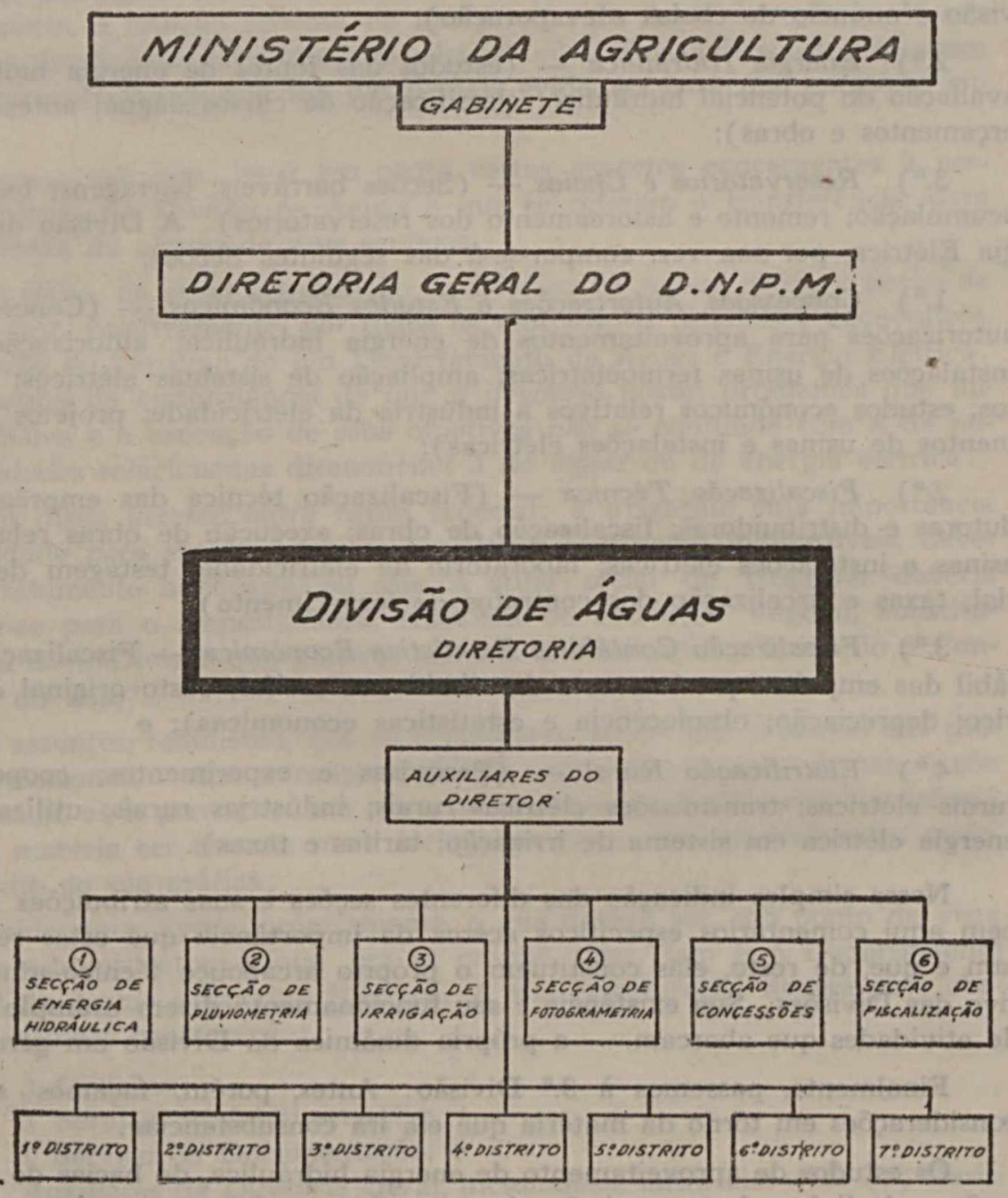




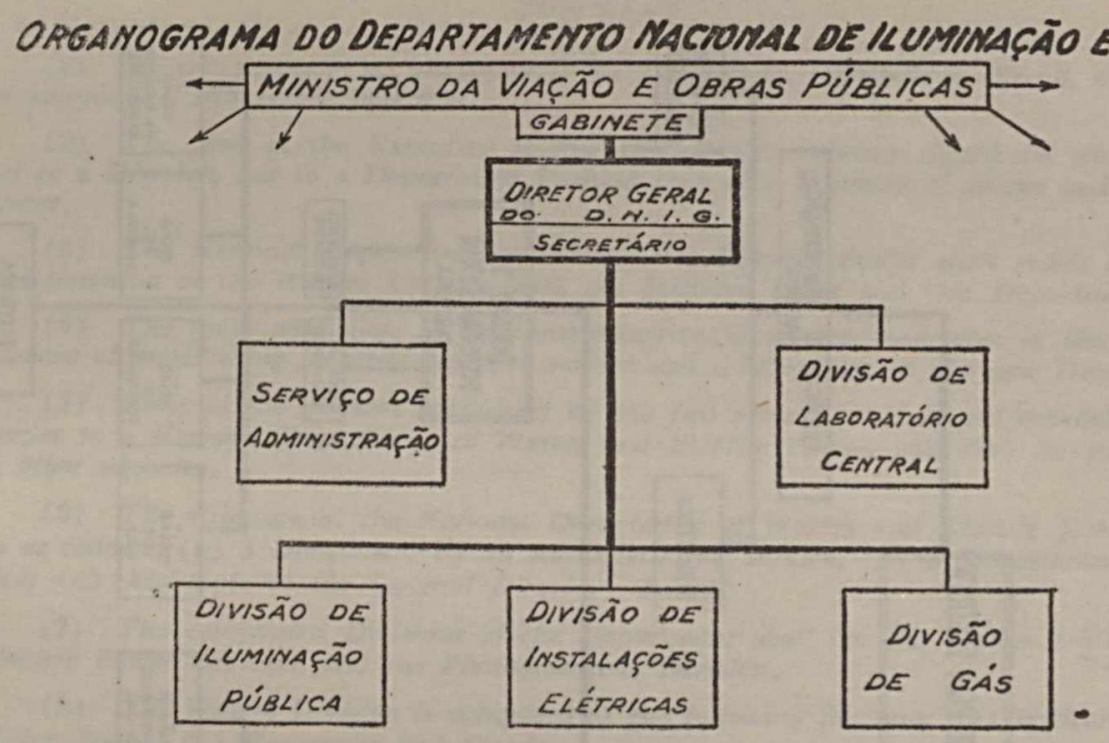

Nos países de vasta extensão territorial (como é o caso do nosso) e de topografia muito acidentada, o emprêgo dos modernos métodos de levantamento aéreo têm que ser intensificado suficientemente.

Por outro lado, hoje em dia, a fotogrametria constitui uma técnica altamente especializada, envolvencio vários setores distintos que se entrosam e que, para atingir a um alto grau de eficiência, no seu emprêgo, precisa obedecer a um comando de especialistas. Acresce, além do mais, a circunstância de ser uma técnica que exige a aplicação de aparelhamento próprio e de difícil utilização.

Tudo isso concorre para que estejamos convencidos de que os assuntos relacionados à organização de mapas necessitam estar reunidos numa Divisão especializada, capaz de realizar com proveito e objetividade o seu importante desiderato.

Diante de tais argumentos é que a nossa proposta inclui a criação da Divisão de Fotogrametria, como uma das componentes do D.N.A.E.E., servida pelas Seções que passaremos a citar e com as respectivas atribuições:

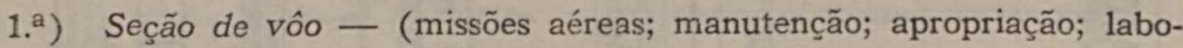
ratório fotográfico e arquivo de fotogramas);

2. ${ }^{a}$ ) Seção de restituição - (projeto de vôc; desenho; foto-cartas e mosaicos);

3. a) Seção de geodésia - (contrôle terrestre e ambulação); e

4. a) Seção de mecânica - (reparơs e fabricação de peças de aparelhos de precisão).

Enfim, são essas as consicierações gerais que poderão servir de subsídio à reforma que se avizinha para os quadros da Administração Pública brasi- 


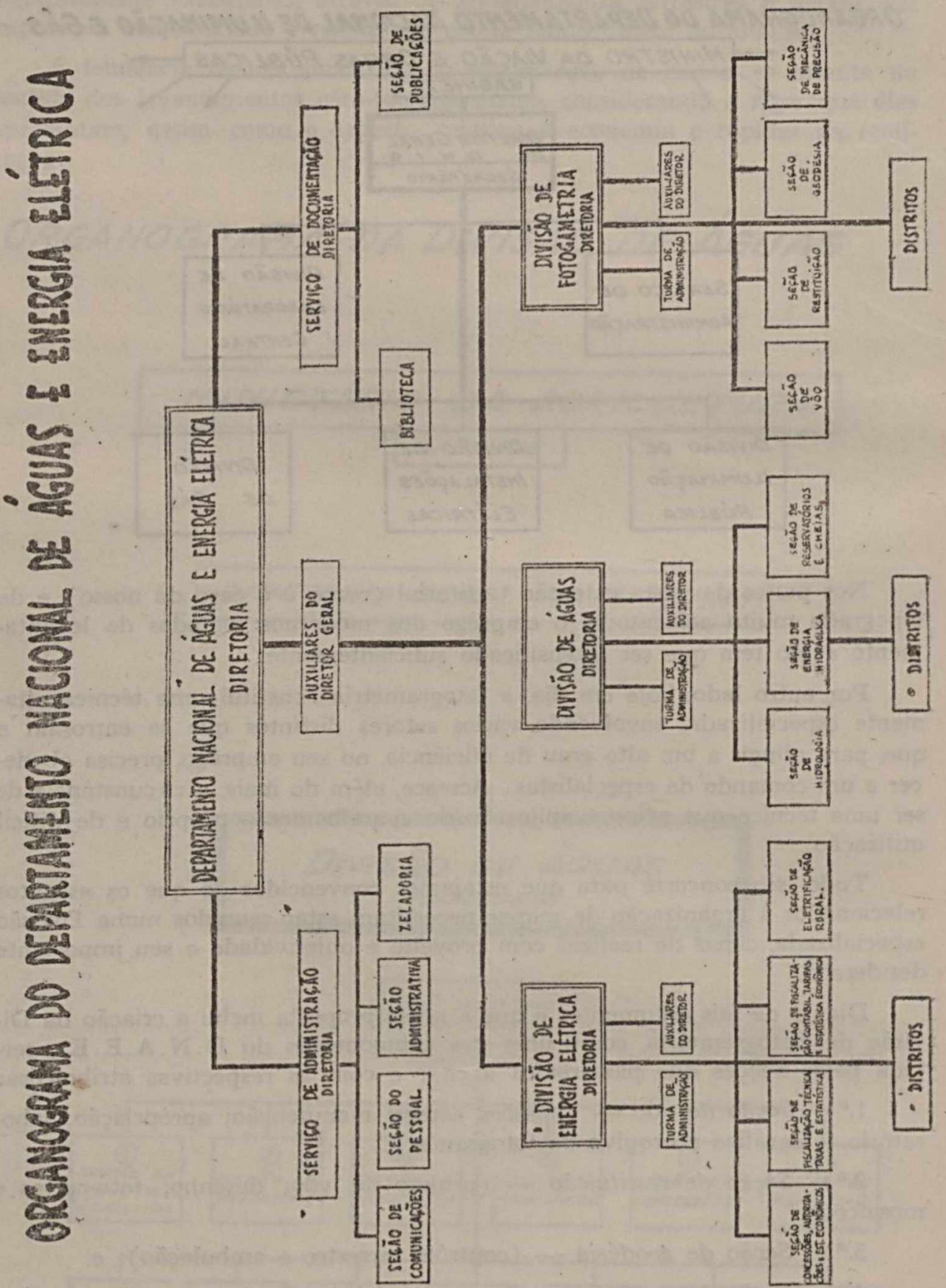

leira - reforma, devemos acentuar, ditada pelas necessidades económicas do país e pela própria evolução da técnica no trato das questões concernentes à energia hidráulica e à indústria da eletricidade. 


\section{SUMMARY}

(1) Electric power is an important factor of progress, especially in Brazil, in view of its enormous viater power potential.

(2) The view of the Executive is that the electric industry should be subordinate, not to a Division, but to a Department forming part of a Ministry of Mines and Electric Power.

(3) The National Department of Waters and Electric Power shall result from the amalgamation of the Waters Division with the National Light and Gas Department.

(4) The main advantage of this amalgamation is an economic one: it obviates the expense of establishing an administrative service and a laboratory in the new Department.

(5) Some of the services performed by the two agenciés to be amal@amated are not proper to a National Department of Waters and Electric Power, and shall be transferred to other agencies.

(6) The structure of the National Department of Waters and Electric Energy shall be as follows: (a) 3 Divisions; (b) an Administrative Service; (c) a Documentation Service; (d) Assistents to the General Director's Board.

(7) The component Divisions of the Department shall be: the Waters Division, the Electric Power Division, and the Photogrametric Division.

(8) The Waters Division is composed of the following Sections: (a) Hydrology; (b) Water Power; (c) Reservoirs and Floods.

(9) The Electric Power Division comprises the following Sections: (a) Concessions, Licenses and Economic Research; (b) Technical Inspection; (c) Accounts Control and Economic Statistics; (4) Rural Electritication.

(10) The Photogrametric Division is a highly specialized one and very important in a country of Great size; its Sections are: (a) Flight Section; (b) Map Section; (c) Geodesic Section; (c) Mechanical Section.

A pesquiza é a principal técnica de que se utiliza o analista administrativo (organizador) para se desincumbir de suas tarefas de planejamento, de aperfeiçoamento das normas e métodos de trabalho e das estruturas organizacionais".

U.S. Bureau of the Budget - "An outline of General Survey Principles and Practices" em "Processes of Organization and Management. 